\title{
Multiple cerebral venous sinus thrombosis in a young male presenting as Status epilepticus
}

\author{
Tuteja H.S ${ }^{1}$, Acharya $S^{2}$, Shukla $S^{3}$ \\ ${ }^{1}$ Dr Harshpreet Singh Tuteja, Resident, Department of Medicine, ${ }^{2}$ Dr Sourya Acharya, Professor, Department of \\ Medicine, ${ }^{3}$ Dr Samarth Shukla, Professor, Department of Pathology, JN Medical College, DMIMSU, Sawangi (Meghe) \\ Wardha, Maharashtra, India.
}

Address for Correspondence: Dr Sourya Acharya, Email: souryaacharya@yahoo.co.in

\begin{abstract}
Background: Cerebral venous thrombosis is a disease with multiple etiologies that present with a remarkably wide spectrum of clinical signs and symptoms. Case report: 38 year old male presented to the emergency department with history of seizures since half hour duration. There was also a history of acute attack of gastroenteritis with multiple episodes of vomiting and diarrhea which was treated by private practitioner. CT scan brain revealed intra parenchymal bleed in left parietal region, possibility of venous infarct. Conclusion: Thrombosis of the sinuses cause intracranial hypertension and raised ICT by impairing the absorption of CSF. This may also further result in hemmorhagic cortical infact like in our case.
\end{abstract}

Key words: cerebral venous thrombosis; status epilpticus; heparin; cranial sinuses.

\section{Introduction}

Cerebral venous thrombosis (CVT) is most likely to occur in adults younger than 45 years old [1]. Prognosis for recovery of function is favourable with early therapeutic intervention. Almost all patients recover to maximum $[2,3]$.

CVT affects all age. There is increase incidence in young women (perhaps reflective of oral contraceptive use and pregnancy) and in aged of both sexes; the women to men ratio is $1: 3: 1$ [3]. There are numerous causes of CVT which include infectious etiologies like intracranial infections, cerebritis. They may be bacterial, fungal, viral and parasitic infection $[3,4]$.

Of non-infective causes, malignancies (meningioma, carcinoid, leukemia, lymphoma), red cell and platelet disorders, inflammatory disease and connective tissue disease are most frequent $[3,4]$. The clinical presented varies with the local and extent of the sinus involved. The most common signs of CVT include headache, pappilloedema, focal motor or sensory deficits and seizure $[4,5,6]$.

\section{Case report}

A 38 year old male presented to the emergency department with history of seizures since half hour duration. Patient was a farm laborer by occupation, had done intense physical exercise for 9-10 hours in the previous week. There was also a history of acute attack of gastroenteritis with multiple episodes of vomiting and diarrhea which was treated by private a practitioner. In the morning he had breakfast and then he started having seizures which was generalized tonic clonic type.

Relatives immediately brought the patient to hospital. Intermittently within this half hour seizures stopped 3 times but there was no regaining of consciousness during this inter ictal period. There was no history of headache, diminution of vision, vomiting, neurodeficit, any drug abuse or fall.

\footnotetext{
Manuscript received $15^{\text {th }}$ July 2016

Reviewed: $27^{\text {th }}$ July 2016

Author Corrected: $10^{\text {th }}$ August 2016

Accepted for Publication $22^{\text {nd }}$ August 2016
} 
General examination revealed; Pulse 120/min, regular, BP- 140/90 mm of $\mathrm{Hg}$. In nervous system examination; patient was drowsy not responding to verbal commands but was responding to deep painful stimulus and moving all four limbs.

Glasgow coma scale was E1V1M5. Deep tendon Reflexes were brisk and plantars were bilateral extensor. Fundus examination revealed papilloedema

After 15 minutes of examination patient again had seizures. Immediately injection lorazepam and loading dose of phenytoin was given which controlled the seizure. CBC, Liver function tests, kidney function tests, Platelet count, c reactive protein, homocysteine levels were normal. Coagulation profile, normal, ANA and double stranded DNA were also normal.

CT scan brain revealed intra parenchymal bleed in left parietal region (fig-1), possibility of venous infarct. MRI VENOGRAM revealed evidence of loss of flow void in superior sagital sinus appearing hypertensive on T1W with corresponding loss of signal intensity on MRV TOF sequences in superior sagital sinus, bilateral transverse sinus and right sigmoid sinus suggesting dural venous thrombosis (Fig- 2-6)

The patient was treated with subcutaneous enoxaparin which was overlapped with oral warfarin, anti convulsants and injection mannitol. In the 7 days of hospital stay patient didn't had any seizure episode. The INR was maintained between 2-3. Enoxaparin was stopped after 5 days. Repeat fundus revealed resolving papilloedema.

Pt was discharged and was called for follow up after a month. A thrombophilia profile was advised after 9 months.

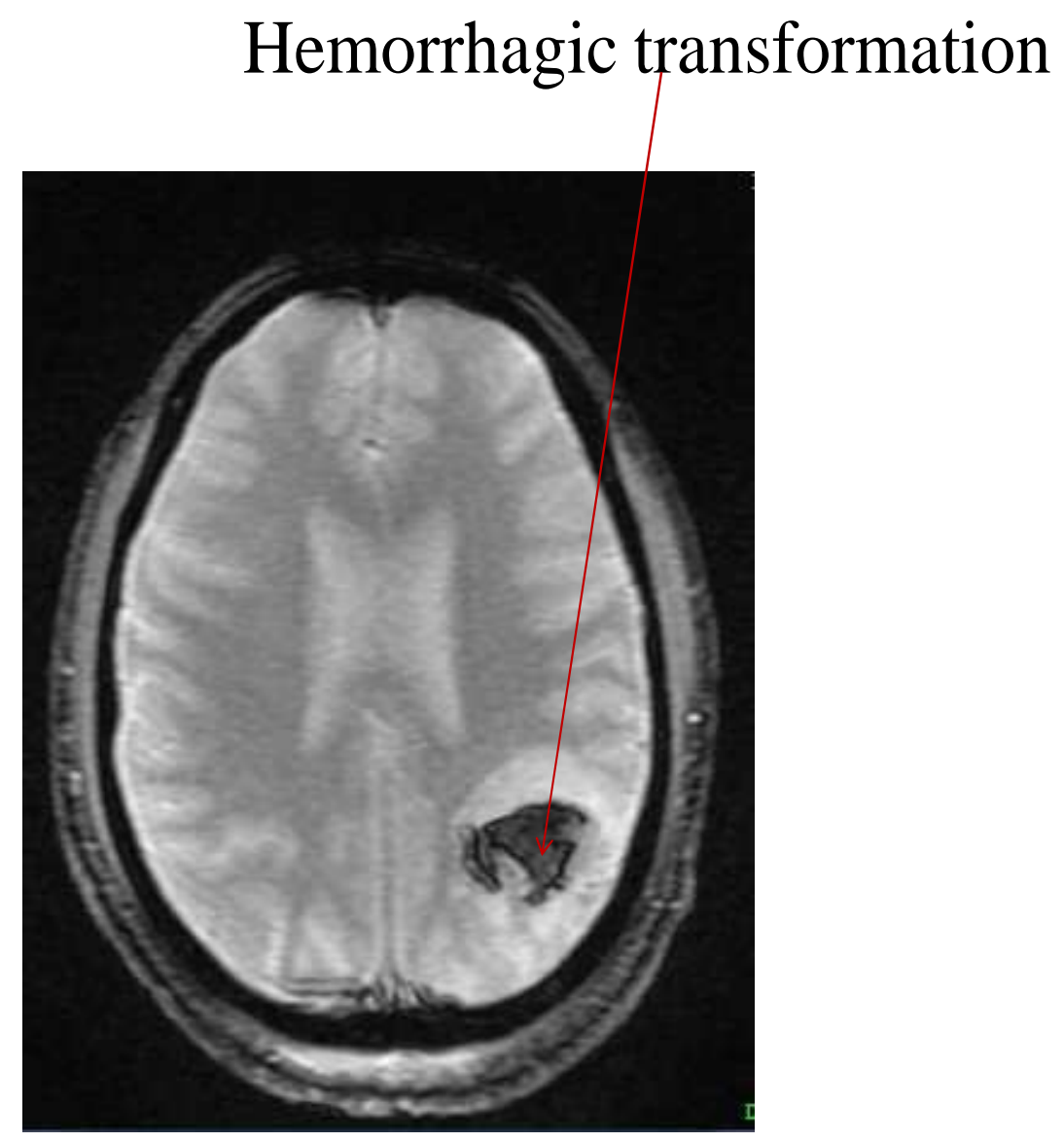



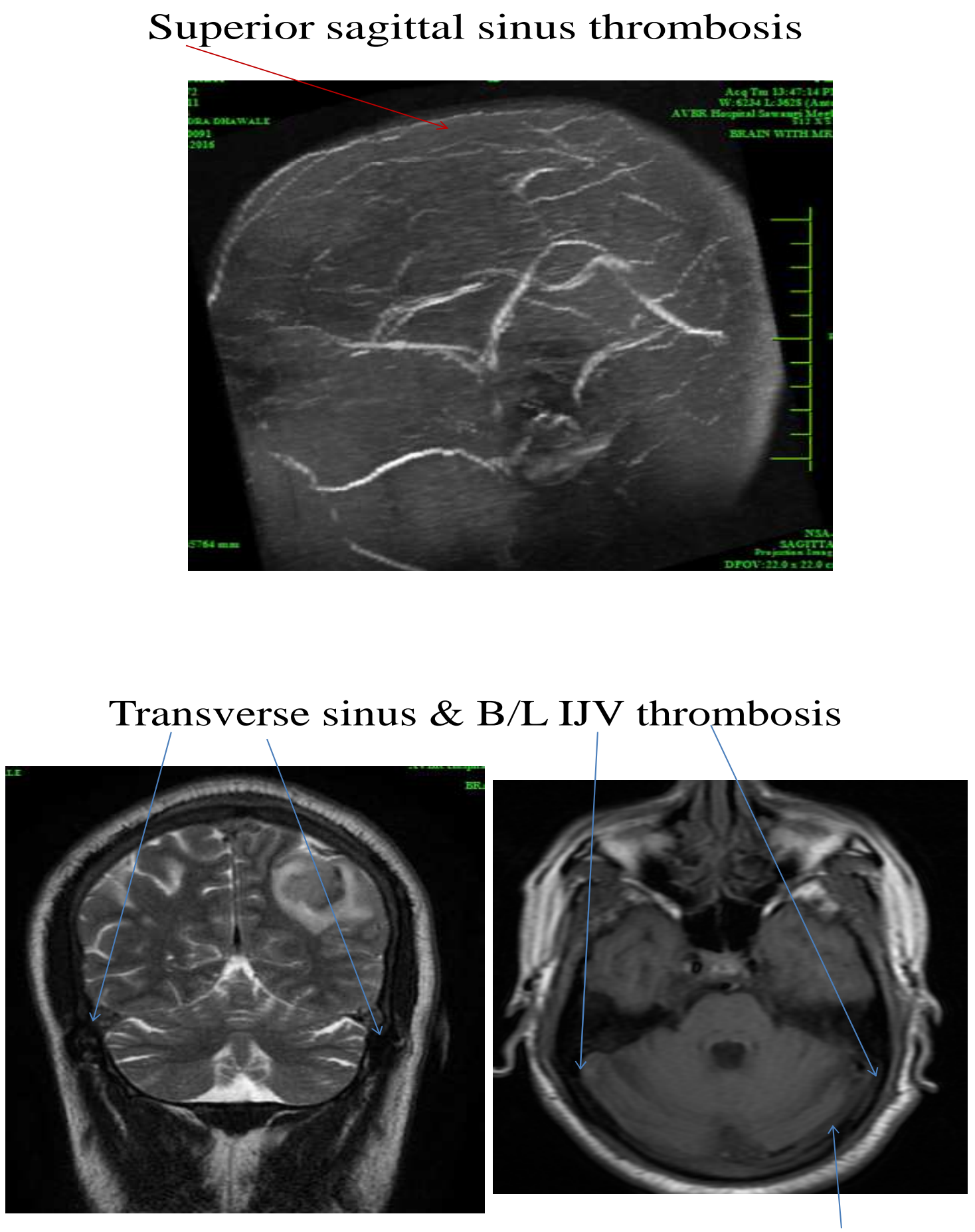

\section{Discussion}

Cerebral venous sinus thrombosis (CVT) is a common neurological emergency. Usually occurs in young less than 45 yr age [1]. With appropriate management all the cases recover [2,3]. The common etiology of CVT are cranial trauma, infection, meningitis, cerebritis, ototis, tonsillitis $[3,4]$. Haematological manifestation like leukemia, lymphoma, myeloproliferative disorders and connective tissue disease can also cause CVT [4]. Inherited thrombopilic stated and hypercaogulable states are other causes. The clinical features depend according to the site and sinus involved. The common signs are headache, neurodeficit and seizure $[3,4,5,6]$. 
Our patient presented with status epilepticus. Thrombosis of the sinuses cause intracranial hypertension and raised ICT by impairing the absorption of CSF. This may also further result in hemmorhagic cortical infact like in our case [4].

We advised thrombophila profile after 9 months the rationale being, antithrombin is decreased by heparin and in the setting of acute thrombosis, Further protein $\mathrm{C}$ and $\mathrm{S}$ levels may be increased in acute thrombosis.

Warfarin therapy also decreases this levels so testing for genetic thrombophilia are usually done after 3-6 months of treatment.

Majority of the secondary cause were ruled out in our case by appropriate investigation. We presume that severe dehydration may have lead to CVT in our case, though a thrombophilia profile is still awaited.

\section{Conclusion}

We presented a case of Cerebral venous sinus thrombosis presented in emergency department with status epilepticus. Patient is recovering well with anticoagulation therapy. Thrombosis of the sinuses cause intracranial hypertension and raised ICT by impairing the absorption of CSF.

This may also further result in hemmorhagic cortical infarct like in our case. Prompt evaluation with radio diagnosis and early treatment with anticoagulation can improve outcome and cause full recovery.
Funding: Nil, Conflict of interest: None initiated, Permission from IRB: Yes

\section{References}

1. Partziguian T, Camerlingo M, Castro L, Censori B, Gazzaniga GC, Belloni G, Mamoli A. Cerebral venous thrombosis in young adults. Experience in a stroke unit, 1988-1994. Ital J Neurol Sci. 1996 Dec;17(6):419-22.

2. Bousser MG, Ross RR. Cerebral venous thrombosis. Vol I. London:WB Saunders; 1997.

3. Ameri A, Bousser MG. Cerebral venous thrombosis. Neurol Clin. 1992 Feb;10(1):87-111.

4. Yatsu FM, editors. Stroke: pathophysiology diagnosis, and management. 2nd ed. New York: Churchill Livingstone; 1992. p. 517-37. Bousser MG, Barnett HJM. Cerebral venous thrombosis. In: Barnett HJM, Mohr JP, Stein BM,

5. Brucker AB, Vollert-Rogenhofer $\mathrm{H}$, Wagner $\mathrm{M}$, Stieglbauer K, Felber S, Trenkler J, Deisenhammer E, Aichner F. Heparin treatment in acute cerebral sinus venous thrombosis: a retrospective clinical and MR analysis of 42 cases. Cerebrovasc Dis. 1998 NovDec;8(6):331-7.

6. Horowitz M, Purdy P, Unwin H, Carstens G 3rd, Greenlee R, Hise J, Kopitnik T, Batjer H, Rollins N, Samson D. Treatment of dural sinus thrombosis using selective catheterization and urokinase. Ann Neurol. 1995 Jul;38(1):58-67.

\section{How to cite this article?}

Tuteja H.S, Acharya S, Shukla S. Multiple cerebral venous sinus thrombosis in a young male presenting as Status epilepticus. Int J Med Res Rev 2016;4(8):1514-1517.doi:10.17511/ijmrr.2016.i08.36. 